\title{
A CONSTRUÇÃO DAS IDENTIDADES NAS SOCIEDADES MULTICULTURAIS: PENSANDO AS APROXIMAÇÕES ENTRE CONCEITOS DO PÓS- COLONIALISMO E A ESCRITORA CHIMAMANDA NGOZI ADICHIE
}

\author{
LA CONSTRUCCIÓN DE LAS IDENTIDADES EN LAS SOCIEDADES \\ MULTICULTURALES: PENSANDO LAS APROXIMACIONES ENTRE CONCEPTOS \\ DEL POSCOLONIALISMO Y LA ESCRITORA CHIMAMANDA NGOZI ADICHIE
}

\author{
THE CONSTRUCTION OF IDENTITIES IN MULTICULTURAL SOCIETIES: \\ THINKING THE SIMILARITIES BETWEEN CONCEPTS OF POSTCOLONIALISM \\ AND THE WRITER CHIMAMANDA NGOZI ADICHIE
}

Nara Eliza MARQUES ${ }^{1}$

RESUMO: Pensar a construção das identidades na contemporaneidade não se limita mais em pensar estruturas engessadas nos tradicionalismos arcaicos e binários. Essa construção, hoje, nos propõe relações cada vez mais complexificadas e alargadas, atomizadas principalmente pelas possibilidades de trânsitos tanto físico/geográfico como de contato e informações. Os limites entre o Ocidente e o resto do mundo já não estão mais tão rígidos e daquilo que ficou conhecido como periferia soam vozes de identificação. Nesse ínterim, o presente texto dialoga com alguns pensadores, principalmente pós-coloniais, com a escritora africana Chimamanda Ngozi Adichie, exemplificando como essas questões se desenvolvem efetivamente na atualidade em uma figura que é a representação do que o Ocidente via como periférico.

PALAVRAS-CHAVE: Identidade. Contemporaneidade. Pós-colonialismo. Atualidade.

RESUMEN: Pensar la construcción de las identidades en la contemporaneidad no se limita más a pensar estructuras engrasadas en los tradicionalismos arcaicos y binarios. Esta construcción, hoy, nos propone relaciones cada vez más complejas y amplias, atomizadas principalmente por las posibilidades de tránsitos tanto físico / geográfico como de contacto e informaciones. Los límites entre Occidente y el resto del mundo ya no son tan rígidos y de lo que se conoce como periferia son voces de identificación. En el ínterin, el presente texto dialoga con algunos pensadores, principalmente postcoloniales, con la escritora africana Chimamanda Ngozi Adichie, ejemplificando cómo estas cuestiones se desarrollan efectivamente en la actualidad en una figura que es la representación de lo que Occidente veía como periférico.

PALABRAS CLAVE: Identidad. Contemporaneidad. Post-colonialismo. Actualidad.

ABASTRACT: Thinking about the construction of identities in contemporary times is no longer limited to thinking structures embedded in archaic and binary traditionalisms. This

${ }^{1}$ Universidade Estadual Paulista (UNESP), Araraquara - SP - Brasil. Mestranda pelo Programa de Pós-Graduação em Ciências Sociais. ORCID: <https://orcid.org/0000-0001-9616-0639>. E-mail: naramarques13@gmail.com. 
construction, today, proposes us increasingly complex and extended relations, atomized mainly by the possibilities of physical / geographic, contact and information transits. The boundaries between the West and the rest of the world are no longer so rigid and what is known as the periphery are voices of identification. In the meantime, the present text dialogues with some post-colonial thinkers, with the African writer Chimamanda Ngozi Adichie, exemplifying how these questions are actually developed today in a figure that is the representation of what the West saw as peripheral.

KEYWORDS: Identity. Contemporaneity. Post-colonialism. Actuality

\section{Introdução}

O presente artigo se propõe pensar sobre a mundialização cultural e a construção de identidades em sociedades multiculturais e para tanto usarei como figura icônica - quase uma 'metonímia' viva - a escritora Chimamanda Ngozi Adichie. Ressalto que me valerei, durante o artigo, de pensar Chimamanda como um todo, porém também apontarei alguns momentos específicos de uma conferência proferida por ela no TED (Ideas Worth Spreading - Vale a pena espalhar ideias) em 2009 na Inglaterra, Oxford, intitulada The danger of single history (O perigo de uma única história).

Essa escolha é feita de maneira pontual, visto que o tema da conferência - além da conferencista já citada - dialoga de maneira direta com os argumentos dos autores acadêmicos que serão usados para embasar esse texto. Para tanto usarei de autores estruturalistas e pósestruturalistas (mais especificamente os pós-coloniais), a saber: 1) Claude Lévi-Strauss, A Antropologia diante dos problemas do mundo moderno (2012); 2) Manuela Carneiro da Cunha, Etnicidade: da cultura residual mas irredutível (2009) e Cultura e "cultura" constante no livro Cultura com Aspas; 3) Marshal Sahlins, O pessimismo sentimental e a experiência etnográfica: por que a cultura não é um 'objeto' em via de extinção (1997). Por outro lado, serão referências expoentes do pensamento pós-colonial: 1) Hommi Bhabha, com o importantíssimo trabalho O Local da Cultura (1998); Stuart Hall, Da Diáspora: identidades e mediações culturais (2003); Arjun Appadurai, As Dimensões Culturais da Globalização (2004). Apresento igualmente a discussão de Sérgio Costa em "Pós-colonialismo e Différance" que compõe o livro Dois Atlânticos: teoria social, antirracismo, cosmopolitismo, o qual reflete sobre os autores pós-coloniais mencionados e as reverberações nas ciências sociais contemporânea.

Dito isto, qual seria então a justificativa maior para me propor um diálogo entre essa escritora que apontei como icônica com os autores citados na sequência? E qual seria o meu 
argumento para apontá-la como icônica, como uma figura que exemplificaria conceitos apresentados nas teorias pós-coloniais?

Meu argumento simples e objetivo é que a Chimamanda é a personificação da interseccionalidade $^{2}$ que as teorias pós-coloniais nos propõem refletir, inclusive Adichie discorre sobre essas interssecionalidades em seus livros ${ }^{3}$, porém se nega a ocupar uma posição “dita acadêmica". Sendo assim, meu argumento já responde as duas questões que coloquei: o diálogo se dará pelo tangenciamento da figura e das atividades de Adichie com as teorias póscoloniais e tal situação automaticamente a coloca como ícone.

\section{Quem é essa mulher?}

Chimamanda Ngozi Adichie é uma escritora nascida na Nigéria em 1977, que tem tido bastante sucesso, repercussão e relevância em seus trabalhos. É pós-colonial por "excelência" tanto na sua existência como nos seus livros. Questionamentos sobre a supremacia do pensamento ocidental eurocêntrico permeiam seus livros e sua vida e com isso nos propõe outras formas de pensar conceitos como tradição e identidade, formas de desconstruir 'epistemes’ que não tem se sustentado mais em uma sociedade em que as relações identitárias são mais complexas e fluídas.

Em uma sociedade mundializada, multicultural, na qual o Estado-nação está em crise e não mais limita nem delimita, não é mais possível pensar dentro da polaridade 'West/Rest' como nos mostra Stuart Hall (1996), binarismos não são mais suficientes para explicar relações construídas de poder. O Rest compõe e ajudou a construir o West e esse discurso está cada vez mais latente.

${ }^{2} \mathrm{O}$ termo interseccional é bastante usado pelo feminismo contemporâneo, e me apreendo dele tanto por essa sua ligação com o feminismo como pela sua significação enquanto o estudo da sobreposição ou intersecção de identidades sociais e sistemas relacionados de opressão, dominação ou discriminação. Alargando, assim, sua abrangência teórica sem perder a sua especificidade.

${ }^{3}$ Em Hibisco Roxo (2003) trata dos problemas sociais enfrentados pela Nigéria através de uma história metafórica de uma garota rica chamada Kambili e um pai violento, autoritário e que se nega a reconhecer as raízes nigerianas; em Meio Sol Amarelo (2006) temos uma história que se passa durante a Guerra do Biafra, que foi motivada por diferenças culturais causadas no país desde a divisão pela colonização europeia; No Pescoço (2009) aborda questões de uma figura feminina, forte, e se passa nos Estados Unidos e na Nigéria. O título do livro faz alusão a uma sensação de sufocamento. Já em Americanah (2013), discorre sobre racismo, xenofobia e desigualdade de gênero nos Estados Unidos, a partir dos protagonistas Ifemelu e Obinze, um casal jovem que vive um romance durante o regime militar nigeriano e Ifemelu se muda para a "Terra do Tio Sam" se deparando com as questões raciais e culturais dos EUA. Sejamos Todas Feministas (2014) e uma palestra sua compilada em livro e assim como em Para Educar Crianças Feministas (2017) se lida com questões de gênero, sobre feminismo, sobre como esse termo é usado como pejorativo e como educamos nossas crianças de maneira machista. 
Adichie traz consigo muito dos 'pós' que iremos abordar: é nigeriana, porém sua formação acadêmica se deu nos Estados Unidos (onde divide morada com seu país de origem), ganhou o título de Master of Arts em Estudos Africanos pela Universidade de Yale, é autora de diversos livros que pensam a mulher, a mulher africana, a mulher africana na 'América' (termo usado erroneamente para designar os Estados Unidos, visto que americanos são todos que vivem nas Américas), o continente africano, o eurocentrismo e assuntos adjacentes. É um sucesso da literatura africana. É pós-feminista, pós-colonial, mãe, palestrante, narradora de histórias. Adichie personifica a identidade alargada e fronteiriça, característica da contemporaneidade, que abordaremos durante o texto:

Se jargão de nossos tempos - pós-modernidade, pós-colonialidade, pósfeminismo - tem algum significado, este não está no uso popular do "pós" para indicar sequencialidade - feminismo posterior- ou polaridade - antimodernismo. Esses termos que apontam insistentemente para o além só poderão incorporar a energia inquieta e revisionária deste se transformarem o presente em um lugar expandido e ex-cêntrico de experiência e aquisição de poder (BHABHA, 1998, p. 23)

Adichie carrega em sua identidade diversas características do 'colonizado' e pensar o colonial a partir dessa mulher vai além do colonialismo contado na história moderna, do sentido linear; é pensar em reconfigurações do campo discursivo, pensar nos diversos colonialismos que passam por gênero, raça, etnia, papel social etc.

Sua existência e suas atividades personificam da melhor forma o pós-colonialismo e, especificamente na palestra indicada acima, em sua fala de aproximadamente 20 minutos, defende que ao contarmos a história de apenas um ponto de vista, legamos ao que ficou em segundo plano um local de pobreza, inaptidão, ignorância. Ela nos propõe a refletir: o que aconteceria se ao invés de contarmos a história dos Estados Unidos a partir da chegada dos ingleses, começássemos contando pela primeira flecha dos índios nativos?

Adichie personifica que as fronteiras que a definiam em uma identidade engessada, em um só espaço, não a limitam e sim são usadas como ponto de partida para a descentralização de teorias, num movimento ‘diaspórico’ de complementação mútua, de retroalimentação, pois sua identidade extrapola seu local de nascimento, suas tradições. Seu movimento migratório é de motivação subjetiva, diferente das migrações das épocas modernas de colonização. O pensamento que antes limitava a identidade a essas características, no pós-colonialismo é superado e a identidade passa a ser um jogo complexo de negociações e influências do qual a tradição é só mais um componente. 
Esse movimento é característico do mundo contemporâneo e, como nos dirá Appadurai (2004), as migrações e as tecnologias de comunicação eletrônica são os sinais diacríticos ${ }^{4}$ da nossa contemporaneidade.

\section{O conceito forjado de modernidade}

Antes de refletirmos sobre o que é essa contemporaneidade somos colocados a pensar, já no primeiro capítulo do livro citado de Appadurai (2004), As Dimensões Culturais da Globalização, que o conceito de modernidade que por muito tempo nos foi dado como inerente/natural - ou qualquer palavra que consiga descrever essa imposição - na verdade é um conceito forjado e que se pretendia de aplicabilidade absoluta:

Para além de tudo o que criou, o projeto iluminista aspirou a criar pessoas que, postfestum, viessem a querer ser modernas. Esta ideia que em si própria se consuma e se justifica provocou muitas críticas e muita resistência, tanto na teoria como na vida cotidiana (APPADURAI, 2004, p. 11).

A sociedade ocidental contemporânea foi fundada na crença do saber empírico e do progresso técnico-científico, seu discurso de saída - utópico, diga-se de passagem - se pautava em uma razão libertária, em uma sociedade funcional e suficiente. Porém resultamos em uma sociedade do consumo, que cria necessidades para gerar trabalho, para produzir e gerar consumo, num ciclo sem fim de destruição dos bens naturais e de alienação do homem. Criamos epidemias e meios de autodestruição em massa, além de doenças incuráveis e indetectáveis de níveis do individual ao social.

A 'razão' submeteu povos e culturas, nos afastou do mítico-mágico, da natureza e aquela, junto ao capitalismo, deu ao homem como objetivo maior de existência a 'corrida pelo ouro'. Essa homogeneização da terra não se sustentaria por muito tempo, pois para haver civilização é necessário um optimum de diversidade, como nos diz Levi Strauss (2012) em sua conferência compilada em "A antropologia diante dos problemas do mundo moderno".

$\mathrm{Na}$ crença de uma história única, a civilização ocidental subjugou muitos povos e culturas acreditando que essas, por serem diversas as suas, estavam num período de 'infância' de uma suposta linha evolutiva civilizacional e que culminaria nisso que vivemos hoje e chamamos progresso.

${ }^{4} \mathrm{O}$ uso desse termo é feito a partir do entendimento de Manuela Carneiro da Cunha no texto Etnicidade: da cultura residual mas irredutível; Cultura e 'cultura' que está no livro Cultura com Aspas (2009, p. 237). 
Esse processo, que Appadurai chama de o momento moderno, é frequentemente reiterado como um momento singular para o autor e resulta em distorções do passado:

Reencarnada como o corte entre tradição e modernidade e tipificada como a diferença entre sociedades ostensivamente tradicionais e sociedades modernas, estápor demais demonstrado que esta posição distorce os significados da transformação e da política do passado (APPADURAI, 2004, p. 13).

Por muito tempo também se acreditou que esses povos subjugados eram apáticos, negava-se a eles a capacidade - mais por falta de opção, do que por opção, visto estarem esfacelados pela violência, inclusive física, decorrente da imposição de uma nova cultura - de fazer dessa sorte madrasta, como nos diz Sahlins (1997), uma nova forma de viver.

\title{
Grupos identitários no pós-colonialismo
}

Porém, é nessa mesma "sorte madrasta" que encontraremos os sinais diacríticos já citados, para então contarmos outras histórias que não vão apenas ao sentido de progresso técnico o ocidental europeu, mas também repensam as relações dos homens, do trabalho, da economia, da natureza, com o mundo.

\begin{abstract}
Depois de Durkheim e do trabalho do grupo dos Années Sociologiques, os "antropólogos aprenderam a considerar as representações coletivas factos sociais, isto é, a vê-las transcender a volição individual, carregadas com a força da moral social e como realidades sociais que eu quero sugerir é que houve nestas últimas décadas uma transformação com base nas transformações do século em que a imaginação se tornou um facto coletivo, social. E esta evolução está por sua vez na base da pluralidade de mundos (APPADURAI, 2004, p. 16).
\end{abstract}

Diversos grupos identitários vêm reivindicando espaço e voz, apresentando-se enquanto agentes ativos para repensar as relações sociais, culturais e do que é entendido como identidade.

Como nos diz Lévi-Strauss na conferência citada, a utopia do progresso ocidental sucumbiu e agora é necessário expandirmos (alargarmos) nossos olhares para outras estruturas culturais se quisermos continuar existindo. E quando falamos em grupos identitários e alternativas não estamos pensando em utopias como à supressão do capitalismo neoliberal e nem em resgatarmos, como um museu ou relicário, culturas que existiram em seus tempos e que não é humanamente mais possível reproduzir.

Para Hommi Bhaba a identificação pela tradição, na contemporaneidade, é parcial: “A representação da diferença não deve ser lida apressadamente como o reflexo de traços culturais 
ou étnicos preestabelecidos, inscritos na lapide fixa da tradição” (BHABHA, 1998, p. 20). É uma negociação complexa que relacionada à capacidade dessa tradição se reinscrever na contemporaneidade:

O reconhecimento que a tradição outorga é uma forma parcial de identificação. Ao reencenar o passado, este introduz outras temporalidades culturais incomensuráveis na invenção da tradição. Esse processo afasta qualquer acesso imediato a uma identidade original ou a uma tradição "recebida" (BHABHA, 1998, p. 21).

Sendo assim o que nos propõe esses grupos é, a partir de agora, pensar novas relações usando como ponto de partida as suas experiências que por muito tempo foram deixadas a margem. Experiências essas que trouxeram nas bagagens diaspóricas, que mantém o grupo e que são importantes para sua individuação e identidade.

A comunicação eletrônica é a rede que dá tessitura a esse contexto:

E estes criam esferas públicas de diáspora, fenômenos que invalidam as teorias ancoradas na hegemonia continuada do Estado-nação como principal árbitro de importantes transformações sociais. Em suma, a comunicação electrônica e as migrações marcam o mundo do presente, não como forças tecnicamente novas, mas como aquelas que parecem impelir (e, por vezes, compelir) a obra da imaginação. Juntas, criam irregularidades específicas porque espectadores e imagens estão em circulação simultânea. Nem as imagens nem os espectadores cabem em circuitos ou audiências que facilmente se confinam a espaços locais, nacionais ou regionais (APPADURAI, 2004, p. 15).

Existem várias formas de se relacionar com o mundo, com a natureza, com os homens e temos visto que o nosso formato atual não parece ser o mais saudável e sustentável, logo está na hora de ouvirmos outras histórias, as histórias dos que ficaram em segundo plano, como nos diz Chimamanda. Por milhares de anos os homens viveram em relações que a sociedade do progresso chamou de infância da civilização e é de se pensar que por esses milhares de anos vivemos em equilíbrio e só apenas a 400 anos de uma maneira que cada dia mais se torna insuportável, desumana.

O pensar a identidade hoje é de uma complexidade não-binária. Já não pensamos em termos como alteridade ou diferença num sentido de distanciamento, como foi na submissão dos povos não europeus, mas sim extrapolamos esses conceitos e passamos pensar nessa identidade como "um encontro com 'o novo' que não seja parte do continum de passado e presente" (BHABHA, 1998, p. 27).

$\mathrm{O}$ conceito de transnacional é inerente à contemporaneidade e figura - nesse artigo especificamente - na imagem de Adichie, que temos acesso pela internet, palestrando em Oxford, Inglaterra, sobre sua experiência de vida como mulher Africana na América do Norte, 
mais exatamente os Estados Unidos, ao mesmo tempo em que por essa experiência 'pessoal' tangencia e discorre sobre características de um imaginário que até um passado recente o ocidente tinha (ou ainda tem?) em relação à África e as diferenças culturais.

\section{Nas periferias do poder}

Atentemos a outra importante característica da nossa contemporaneidade que também figura em Chimamanda, a proposição em seu discurso, como vai nos apontar Costa (2003), não é de ocupar um lugar de paladina dos subalternos, mas sim:

[...] que "ouve" a voz desses, ecoada nas insurgências heroicas contra a opressão, o intelectual pós-colonial busca entender a dominação colonial como cerceamento da resistência mediante a imposição de uma episteme que torna a fala do subalterno, de antemão, "silenciosa", vale dizer, desqualificada. Trata-se, portanto, não de dar voz ao oprimido, mas como definem Pieterse e Parekh (1995, p. 12), de uma descolonização da imaginação o que implica uma crítica que não seja simplesmente anticolonialista (COSTA, 2003, p. 120121).

O pós-colonialismo nos propõe uma modernidade entrelaçada que pensa o colonizado não como o outro, mas como parte essencial dessa construção. Nós não temos mais apenas uma história possível. A concepção de progresso que utilizamos é forjada, reforçada principalmente a partir do advento da Revolução Industrial e para que tenhamos novas possibilidades de 'progresso' é necessário que cada vez mais as identidades estejam sendo negociadas, alargadas:

\footnotetext{
Essa localidade está mais em torno da temporalidade do que sobre a historicidade: uma forma de vida que é mais complexa que "comunidade", mais simbólica que "sociedade", mais conotativa que "país", menos patriótica que patrie, mais retórica que a razão de Estado, mais mitológica que a ideologia, menos homogênea que a hegemonia, menos centrada que o cidadão, mais coletiva que "o sujeito", mais psíquica do que a civilidade, mais hibrida na articulação de diferenças e identificações culturais do que pode ser representado em qualquer estruturação hierárquica ou binária do antagonismo social (BHABHA, 1998, p. 199).
}

Appadurai nos fala de uma teoria da ruptura e para compreendermos essa teoria temos que ultrapassar, inclusive, muito do pensamento estruturalista, que apesar de dissolver o sujeito cartesiano e o sujeito sociológico clássico, não ultrapassa o limite de uma dualidade 'nós e os outros'. Pensarmos em uma sociedade multicultural, em que a comunicação social e as migrações são seus sinais diacríticos, dotada não apenas de um interesse objetivo, mas sim de 
uma subjetividade características dos dias atuais faz com que não mais consigamos separar apenas entre uns e outros, entre cultura e tradição.

Essa teoria da ruptura ultrapassa também a interpretação que temos do conceito de diferença e sua complexidade resulta em alterações de paradigmas epistemológicos há muito engessados nas nossas construções sociais. Essa teoria propõe, por exemplo, o direito de significação da periferia a partir da si mesma:

A representação da diferença não tem de ser interpretada apressadamente como um conjunto pré-fornecido de caracteres étnicos ou culturais no âmbito de um corpo fixo da tradição. Da perspectiva da minoria, a articulação social da diferença representa uma complexa negociação em curso que busca autorizar os hibridismos que aparecem nos momentos de transformação histórica. O "direito" de significar a partir da periferia do poder autorizado e privilegiado não depende da persistência da tradição; tal direito está fundado no poder da tradição de ser reinscrita por meio das condições de contingência e contradição que respondem às vidas daqueles que "estão em minoria" (COSTA, 2003, p. 122).

Adichie também se apresenta como representação viva da citação acima, por si só é uma figura composta por várias características periféricas e, como já dissemos anteriormente, é africana, mulher, mãe, negra e imigrante, logo a sua voz ecoa da periferia do poder e tem sido significante.

Porém nos atentemos a um detalhe bastante importante que vemos nas teorias póscoloniais: apesar de nos alertarem sobre os perigos de uma única história - me apropriando propositalmente do título da palestra de Chimamanda - os autores aqui citados não acreditam “na simetria de poder e em iguais possibilidades de influência mútua entre o 'Ocidente' e o resto do mundo" (COSTA, 2003, p. 120), porém isso não significa que não se possa resistir à dominação e entender que as partes que até então foram nos dadas como contrárias na verdade se completam, se compõe.

Adichie é a periferia e fala sobre a periferia do poder de dentro do centro do poder: Estados Unidos e Inglaterra, por exemplo e, de dentro do centro do poder, é a différance cunhada por Derrida e citada por Costa, ou seja, essa diferença que não consegue ser traduzida por signos, que não é binária, que não cabe no universalismo étnico e cultural proposto pelo modernismo. É a mistura e a hibridez proposta pelo pós-colonialismo.

\section{Considerações finais ou a perda de absolutos}


Segue abaixo um trecho da conferência de Chimamanda onde ela discorre sobre o momento em que entendeu que as experiências que via nos livros não representavam a sua realidade:

Então, eu fui uma leitora precoce. E o que eu lia eram livros infantis britânicos e americanos. Eu fui também uma escritora precoce. E quando comecei a escrever, por volta dos sete anos, histórias com ilustrações em giz de cera, que minha pobre mãe era obrigada a ler, eu escrevia exatamente os tipos de histórias que eu lia. Todos os meus personagens eram brancos de olhos azuis. Eles brincavam na neve. Comiam maçãs. (Risos da plateia) E eles falavam muito sobre o tempo, em como era maravilhoso o sol ter aparecido. (Risos da plateia), apesar do fato que eu morava na Nigéria.

Eu nunca havia estado fora da Nigéria. Nós não tínhamos neve, nós comíamos mangas. E nós nunca falávamos sobre o tempo porque não era necessário. Meus personagens também bebiam muita cerveja de gengibre porque as personagens dos livros britânicos que eu lia bebiam cerveja de gengibre. Não importava que eu não tivesse a mínima ideia do que era cerveja de gengibre. (Risos da plateia) E por muitos anos depois, eu desejei desesperadamente experimentar cerveja de gengibre. Mas isso é outra história. A meu ver, o que isso demonstra é como nós somos impressionáveis e vulneráveis em face de uma história, principalmente quando somos crianças. Porque tudo que eu havia lido eram livros nos quais as personagens eram estrangeiras, eu convenci-me de que os livros, por sua própria natureza, tinham que ter estrangeiros e tinham que ser sobre coisas com as quais eu não podia me identificar. Bem, as coisas mudaram quando eu descobri os livros africanos. Não havia muitos disponíveis e eles não eram tão fáceis de encontrar quanto os livros estrangeiros, mas devido a escritores como Chinua Achebe e Camara Laye eu passei por uma mudança mental em minha percepção da literatura. Eu percebi que pessoas como eu, meninas com a pele da cor de chocolate, cujos cabelos crespos não poderiam formar rabos-de-cavalo, também podiam existir na literatura. Eu comecei a escrever sobre coisas que eu reconhecia. Bem, eu amava aqueles livros americanos e britânicos que eu lia. Eles mexiam com a minha imaginação, me abriam novos mundos. Mas a consequência inesperada foi que eu não sabia que pessoas como eu podiam existir na literatura. Então o que a descoberta dos escritores africanos fez por mim foi: salvou-me de ter uma única história sobre o que os livros são (ADICHIE, 2009).

Esse fragmento ilustra o que Bhabha especificou como a perda de absolutos. As migrações e a comunicação em massa possibilitaram que a luta pelo reconhecimento de outras histórias ficasse mais latente. As articulações que essas duas instâncias hoje provocam desmontam categorias antes inquestionáveis e dá voz a espaços antes silenciados.

Todas essas histórias fazem de mim quem eu sou. Mas insistir somente nessas histórias negativas é superficializar minha experiência e negligenciar as muitas outras histórias que me formaram. A "única história cria estereótipos". E o problema com estereótipos não é que eles sejam mentira, mas que eles sejam incompletos. Eles fazem uma história tornar-se a única história (ADICHIE, 2009). 
Tanto Bhabha, Hall, Appadurai quanto Adichie são todos imigrantes das periferias do poder e que se movimentaram para o centro do poder para entender porque uma só história é contada. Esse movimento, conforme já citado, de desconstrução não de um passado, mas de tudo que é passado, de quebra de binarismos, cria o que Bhabha chamou de 'terceiro espaço' e corresponde ao contexto "no qual a contingência espacial das fronteiras nacionais e raciais é combinada com o que ele descreve como a contingência temporal do indecifrável" (COSTA, 2003 apud PHILIPS, 1999, p. 68).

A movimentação geográfica unida às novas tecnologias de comunicação, que também contribui para o rompimento de limites de geográficos e criam maiores interações, faz surgir das frestas dos discursos hegemônicos, o discurso do 'terceiro espaço' e essa voz não prevê a supressão do discurso do colonizador para a ascensão do discurso do colonizado - o que incorreria em um novo binarismo às avessas - mas sim de compor com as histórias já contadas, sempre nos atentando aos perigos de uma única história.

Ouso a aproximar a escritora, figura real, existente e ativa, Chimamanda Ngozi Adichie com a personagem Aila que Bhabha nos aponta em seu texto.

Aila, como mulher de cor, define uma fronteira que está ao mesmo tempo dentro e fora, o estar de fora de alguém que, na verdade, está dentro. A quietude que a cerca, as lacunas em sua história, sua hesitação e paixão que falam entre o eu e seus atos - estes são momentos em que o privado e o público se tocam em contingência. Eles não transformam simplesmente o conteúdo de ideias políticas; o próprio "lugar" de onde o político é falado - a esfera pública mesma, torna-se uma experiência de liminaridade que, nas palavras de Sonny, questiona o que significa falar "a partir do centro da vida" (BHABHA, 2003, p. 36-37).

Ambas são figuras limites que transitam entre os binarismos obsoletos da modernidade sem ser possível fixá-las em uma só forma, figuras estas, que segundo os estereótipos, estariam na periferia mais distante do centro na concepção eurocêntrica, mas que escorregam, migram do centro para a periferia, do público ao privado, de fora para dentro e vice-versa em uma identidade fluída e política, que aos poucos vai desconstruindo a imaginação colonizada para si e para os outros, para os colonizadores e para os que foram colonizados.

É a partir dessa reflexão que entendemos qual é o grande exercício da contemporaneidade. Entendemos o que nos propõe o pós-colonialismo que conforme dito acima, não é acabar com o passado, mas sim com qualquer forma de passado, é necessário que descolonizemos nossa forma de pensar, que complementemos os estereótipos, que transitemos 
entre as categorias pré-definidas até que elas percam essas formas e resultemos em uma solidariedade pautada nos encontros.

\section{REFERÊNCIAS}

ADICHIE, Chimamanda Ngozi. The danger of single history. TED - Ideas Worth Spreading, 2009, Inglaterra, Oxford (O perigo de uma única história). Disponível em: https://www.geledes.org.br/chimamanda-adichie-o-perigo-de-uma-unica-historia/. Acesso em: 12 jun. 2018.

APPADURAI, Arjun. Aqui e Agora. In: APPADURAI, Arjun. As Dimensões Culturais da Globalização. Lisboa: Teorema, p. 11-40, 2004.

BHABHA, Homi. DissemiNação: o tempo, a narrativa e as margens da nação moderna. In: BHABHA, Homi. O Local da Cultura. Belo Horizonte: EdUFMG, p. 198-238, 1998.

BHABHA, Homi. Introdução: Locais da Cultura. In: BHABHA, Homi. O Local da Cultura. Belo Horizonte: EdUFMG, p. 19-42, 1998.

CARNEIRO DA CUNHA, Manuela. Etnicidade: da cultura residual mas irredutível; Cultura e "cultura"". In: CARNEIRO DA CUNHA, Manuela. Cultura com Aspas. São Paulo: Cosac Naify, p. 233-244, 2009.

COSTA, Sérgio. Pós-colonialismo e Différance. In: COSTA, Sérgio. Dois Atlânticos: teoria social, anti-racismo, cosmopolitismo. Revista Brasileira de Ciências Sociais - Vol. 21 N $^{\circ}$. 60. 2003.

HALL, Stuart. Pensando a Diáspora: reflexões sobre a terra no exterior. In: HALL, Stuart. Da Diáspora: identidades e mediações culturais. Belo Horizonte: EdUDM, p. 25 -50, 2003.

LÉVI-STRAUSS, Claude. A Antropologia diante dos Problemas do Mundo Moderno. São Paulo: Companhia das Letras, 2012.

SAHLINS, Marshall. "O pessimismo sentimental" e a experiência etnográfica: por que a cultura não é um "objeto" em via de extinção (Parte I). Mana. Estudos de Antropologia Social. Vol. 3, nº 1. Rio de Janeiro: Museu Nacional, p. 41-73, 1997.

\section{Como referenciar este artigo}

MARQUES, Nara Eliza. A construção das identidades nas sociedades multiculturais: pensando as aproximações entre conceitos do pós-colonialismo e a escritora Chimamanda Ngozi Adichie. Rev. Sem Aspas, Araraquara, v.7, n.2, p. 182-193, jul./dez., 2018. ISSN: 2358-4238. DOI: 10.29373/sas.v7i2.12227

Submetido em: 06/02/2019

Aprovado em: 09/04/2019 